\title{
Investigating Learners' Use and Understanding of Peer and Teacher Feedback on Writing: a Comparative Study in a Chinese English Writing Classroom
}

\section{Introduction}

In the past two decades, peer feedback has been increasingly used in ESL/EFL (English as a Second/Foreign Language) writing instruction. This has given rise to research on whether and how peer feedback assists ESL/EFL learners in developing their writing proficiency, mainly through the lens of socio-cultural theory. In this theoretical framework, human intellectual capacities such as language development are suggested to be socially and culturally mediated within the Zone of Proximal Development (ZPD) (Lantolf, 2000; Lantolf \& Thorne, 2006; Villamil \& Guerrero, 2006; Vygotsky, 1978). The ZPD is defined as "the distance between the actual developmental level determined by independent problem solving and the higher level of potential development determined through problem solving in collaboration with more capable peers or seniors. (Vygotsky, 1978, p.86) ". In language learning, Foster and Ohta (2005) defined the ZPD as "the distance between the actual developmental level as determined by individual linguistic production, and the level of potential development as determined through language produced collaboratively with a teacher or peer (p.144)". The ZPD therefore suggests that ESL/EFL learners could potentially facilitate the development of their peers' ESL/EFL proficiency.

This notion has been substantiated in empirical studies on the use of peer feedback in ESL/EFL writing where a comparative approach between peer and teacher feedback was predominantly used. Consistent findings were reported. Connor and Asenvage (1994) observed $5 \%$ of revisions that were based on peer feedback, in contrast with $35 \%$ based on teacher feedback (with the rest in response to self-corrections). Paulus (1999) reported that 
the twelve undergraduate ESL learners in his pre-freshmen composition class incorporated $87 \%$ of the total amount of teacher feedback, against $51 \%$ for peer feedback. Likewise, the twelve Chinese college EFL learners in Yang et al's (2006) study also used more teacher feedback $(90 \%)$ than peer feedback $(76 \%)$ in their redrafts. In line with college ESL/EFL learners, Tsui and $\mathrm{Ng}$ (2000) observed that the secondary ESL learners in their study also used more teacher than peer feedback in their redrafts. We could therefore observe that ESL/EFL learners favour teacher feedback over peer feedback when revising their drafts.

The priority given to teacher feedback is explained with learners' affective preference for teacher feedback over peer feedback. For instance, Zhang (1995) asked 81 Asian college EFL learners to make a choice among teacher-, peer- and self-feedback after full exposure to these three types of feedback. Seventy-six (94\%) students preferred teacher to peer- or self-feedback. His finding was corroborated by Carson and Nelson (1996) and Nelson and Carson (1998) of six ESL college students (including three from China). All participants in their studies favoured teacher feedback because they believed that teachers possessed a better knowledge of English language and could therefore provide more helpful feedback than peer learners. A similar claim was made by the twelve Chinese college EFL learners in Yang et al (2006): They fully confirmed the value of teacher feedback but held reservation about the value of peer feedback for the improvement of their final writing because they believed teacher feedback was more accurate, more to the point, and more trustworthy than peer feedback.

However, learners' affective preference for teacher feedback might lead to learners' use of teacher feedback without full understanding. Hyland (1998), via retrospective interviews about the use of teacher feedback in ESL learners' writing revisions, noted that at times 
learners revised their drafts with teacher feedback with no real understanding of why the teacher feedback was provided. Likewise, the ESL learners in Goldstein (2006) also admitted in interviews that they sometimes used teacher feedback for their redrafts without understanding its necessity. Lee (2007) ascertained through interviewing six teachers and eighteen secondary school students in Hong Kong that the students sometimes copied teacher feedback in their revisions without thinking about why; as a result, the students made similar mistakes in their subsequent writing tasks.

Learners' use of feedback without full understanding poses a challenge to the existing research enquiry that suggested the relative value of peer to teacher feedback mainly in terms of the amount of peer and teacher feedback that was used in learners' redrafts. As Lantolf (2003) argues, the key to the language development with other regulation lies in its successful internalisation. Internalisation refers to the process through which learners construct a mental representation of what was at one point physically presented (acoustic or visual) in external form (Lantolf, 2003, p.351). Internalisation that results in an exact copy of the external on the internal plane would be meaningless and there could be no mental development (Lantolf \& Thorne, 2006, p.155). This echoes in the field of writing as the key to the development of ESL/EFL writing with peer and teacher feedback lies in learners' understanding of peer and teacher feedback. Feedback that is used/copied but ununderstood may help to improve writing quality but does not necessarily contribute to the development of learners' long-term writing proficiency.

\section{Current study}

The current study distinguished learners' use of peer and teacher feedback from learners' understanding of peer and teacher feedback. Eighteen second-year English majors 
and their writing teacher at a large university in south China participated in this case study research for 16 weeks $\left(28^{\text {th }}\right.$ February $-21^{\text {th }}$ June 2006). The following three research questions were examined:

1. Which type of written feedback did the students use more frequently in their revisions, peer feedback or teacher feedback?

2. Which type of written feedback did the learners understand better, peer feedback or teacher feedback?

3. What factors, if any, were reported to influence learners' decision-making process of dealing with peer and teacher feedback?

To answer the questions, three research methods were adopted: (a) content analyses of learners' first and revised drafts to examine learners' use of peer and teacher feedback, (b) stimulated recall interviews (SRIs) to investigate learners' understanding of peer and teacher feedback, and (c) interviews with the learners to look for factors that affected learners' responses to peer and teacher feedback.

\subsection{Research context}

Three traits of the research context are described here: (a) existing English writing pedagogy in the researched institution, (b) the background of participants, and (c) the procedure of integrating peer feedback with existing teacher feedback.

\subsubsection{Existing writing pedagogy in the researched institution}

To understand the existing writing pedagogy in the researched institution and because of few studies specified to English writing pedagogy in Chinese universities, interviews were conducted with the eighteen participating students and all the six Chinese English writing teachers who had a three to ten year working experiences in that institution. A 
general interview question was asked: How do you describe your writing instruction? In addition, observation was conducted in ten English writing classes instructed by the six teacher interviewees.

Based on the three data sets (i.e. student interview data, teacher interview data and classroom observation data), the following features were observed:

1. One draft and one mark: Since the examination essay was a one-shot activity, learners were required to submit one draft for each writing task. The teacher gave the draft a mark, and sometime added several lines of general comments.

2. Heavily used textbooks: Textbooks were heavily used in class. Most writing topics came from the textbooks. Model essays in the textbooks were frequently used to teach how to write a high mark examination essay.

3. Silent class: Few interactions occurred between and among learners in the writing class. Teachers talked through the class time.

4. Teachers as the only assessment agent: Since teachers were the only legitimate assessors of students' examination essays, teachers and students seemed to take it for granted that teachers should be the sole assessors of students' writing.

We could thereby observe a strong assessment culture within the existing writing pedagogy in the institution: The learning and teaching of writing seemed to be geared towards preparing examination essays.

To alter such an examination-oriented and teacher-driven writing pedagogy, peer feedback and multiple-draft writing were introduced into the program, aiming to make writing assessment as a tool for learning rather than focusing exclusively on examination standards. The writing class in this study was for second-year English majors, instructed by 
a writing teacher from the United States. Before collecting the data, the researcher discussed with the teacher how peer feedback could be integrated with the existing teacher feedback. This meeting brought about the procedure of peer feedback depicted next.

\subsubsection{Procedure of integrating peer feedback with existing teacher feedback}

Peer feedback was provided in normal writing classes. A class consisted of two sessions, each session lasting for 45 minutes with a ten-minute break in the middle. In the first session, the writing teacher (a) returned the students' last assignment, (b) asked the students to read his comments, (c) explained the comments to learners who asked for help, and (d) summarised commonly made mistakes.

Peer feedback was integrated in the second session with the following steps. The teacher

1. assigned each student with a number between1-9.

2. paired the students who had the same number. (When learners were asked to choose between working in group and working in dyad, they chose to work in dyad.)

3. allocated 15 minutes for students to read and offer written feedback on their partners' writing.

4. allocated 25 minutes for the students to discuss the provided feedback. (Three pairs were recorded in each writing class. Priority was given to students who were not recorded in the last writing class in order to vary students with each writing task.)

5. collected students' first drafts which contained peer written feedback.

After the peer feedback session, teacher feedback was provided outside class. The teacher provided comments on learners' first drafts and the peer feedback on the drafts (see Appendix A). He also held conferences with the six recorded students. Each 
conference session lasted for about fifteen minutes, a similar time span as that was allocated for peer interaction. In conferences, learners were encouraged to elicit clarifications of teacher feedback that they felt confused. Assignments were returned in the next class when learners were asked to revise their drafts with peer and teacher feedback outside class.

The teacher insisted on providing comments on peer feedback in order to avoid misleading students by inappropriate peer feedback. Although the researcher was aware that the teacher's comments on peer feedback might influence learners' incorporation of peer feedback in their redrafts, she consented to the provision for two reasons. For one thing, empirical studies have substantiated the transfer of incorrect peer feedback to learners' revised drafts (e.g. W. Cheng \& Warren, 2005; Nelson \& Carson, 1998; Patri, 2002). For another thing, it was expected that giving consent to the provision of teacher comment on peer feedback could maintain the teacher's devotion to this research, as Stake (1995) suggests that participants' hospitality to the enquiry should be regarded as a first criterion for selecting cases so that we could maximise what we could learn. It is also noteworthy that although the essential role of training in peer feedback has been widely discussed in the relevant empirical studies (Berg, 1999; Hansen \& Liu, 2005; Hu, 2005; Min, 2005; Rollinson, 2005; Stanley, 1992; Zhu, 1995), the teacher maintained that learning was a self-discovery journey and learners would learn how to provide helpful peer feedback after a time. The students therefore did not receive step-to-step training in how to provide peer feedback.

\subsubsection{Background of participants}


The participants consisted of eighteen second-year English majors (ten females and eight males) in a writing class. They gained an average score of 120 out of 150 in the entrance English examination (which roughly corresponds to a score of 6-6.5 on IELTS), according to the official statistics held by the institution. They were labelled as intermediate English learners by their writing teacher. The teacher had taught English in China for over two years by that time. Before this, he was a professor in an American college for over 30 years.

Due to the prevailing teacher-driven and examination-oriented writing pedagogy in the students' previous writing classes as discussed in Section 2.1.1, students had few experiences in providing or receiving peer feedback in writing classes. The writing teacher had also never used peer feedback in English writing classes.

\subsection{Data collection and analysis methods}

The data consisted of learners' first and revised drafts, peer and teacher feedback on first drafts, student stimulated recall interview data and semi-structured student interview data.

\subsubsection{Feedback and revision data}

In line with the existing studies, this case study research used learners' first and revised drafts to locate the feedback instance that was incorporated in revisions.

Twenty-six students' assignments were selected and photocopied, covering a wide range of genres (i.e. poem, argument, letter, research paper, and fiction). The assignments were selected with four criteria. Firstly, the assignments comprised a first and revised draft. Secondly, the revised draft contained the evidence of the use of peer and teacher feedback; that is to say, assignments with revised drafts which were totally different from their first 
drafts were excluded. Thirdly, the assignments were discussed in class between learners and then in teacher-student conferences outside class (see Section 2.1.2). Finally, the writers attended stimulated recall interviews. Table 1 depicts the distribution of the 26 assignments across the students.

The 26 assignments were analysed by taking each feedback instance as the unit of analysis. Feedback consisted of symbols and marks in the margin, underlines of problems, corrections, and detailed text-specific comments and suggestions which could trigger revisions (see Appendix A). Feedback in the first draft was classified into peer feedback (PF) and teacher feedback (TF). Feedback was then cross-linked to the revisions in the redrafts and was categorised as used and not used. Therefore, four categories were yielded: PF/used, PF/not used, TF/used and TF/not used.

\subsubsection{Stimulated recall interviews (SRIs)}

SRIs have been widely used in education research to explore what happens in learners' mind when they respond to a learning task (e.g. oral interaction, reading passages, and the process of writing) (Gass \& Mackey, 2000). However, few studies have adopted SRIs to investigate learners' understanding of peer and teacher feedback in ESL/EFL writing.

This study employed SRIs as a means of helping learners vocalise their understanding of the feedback that was integrated in their revisions. In total, 26 SRI data sets based on the 26 assignments were collected, using the feedback on the first draft and the revisions in the redraft as the stimuli.

Before conducting SRIs, the recall questions were piloted with three students different from the target SRI interviewees. Gass and Mackey (2000) suggested three benefits for piloting SRI questions: 
1. Lead to revisions and fine-tuning of the protocol.

2. Help to avoid costly and time-consuming problems during the data collection procedure.

3. Help to avoid the loss of valuable, potentially useful and often irreplaceable data. The pilot brought about the following SRI questions:

1. Could I help you with any feedback instance that you felt confused?

2. I noticed you changed this language point here. What were you thinking when you changed it?

3. I noticed you deleted this part. What were you thinking when you deleted it?

The first question was designed to invite the students to identify feedback instances that were not fully understood. Although the interviewees covered feedback that was used and that was discarded, the data analyses only focused on the feedback that was used because this study targeted at the feedback that was used but un-understood to distinguish learners' use and understanding of feedback. The last two questions were oriented to the feedback that was used in revisions but was not mentioned in interviewees' responses to the first question.

The SRIs were conducted in students' first language (i.e. Mandarin Chinese) because the student interviewees believed that using Chinese could make them understood better. A translated and back-translated process was followed to convert the Chinese SRI data into English (Chapman \& Carter, 1979).

The SRI data were archived, analysed and thematically organised with the use of NVivo2 (Richards, 1999). Feedback was categorised as understood and not understood. Feedback was labelled as understood if a legitimate reason was given for its use in redrafts. 
Feedback was identified as not understood if it was (a) asked in interviewees' response to the first SRI question or (b) no legitimate reason was given for its use in revisions in interviewees' responses to the last two SRI questions.

The extract below demonstrates how the SRI data were coded with regard to understood and not understood. It derived from Jin's essay titled Parental Love. The original sentence, teacher feedback on the sentence, and the revised version of the sentence, are shown below:

The original sentence: $\underline{\text { Virtually, there is boundless love hidden in fishbone. }}$ Look up meaning? The revised sentence: Actually, there is boundless love revealed by fishbone. [J(Jin): the student; R: Researcher] (SRI/06062006/Jin/L1-24)

1. R: Do you need help with the feedback received in the first paragraph?

2. J: Yes, this one. What's the difference between 'virtually' and 'actually'?

3. I was suggested by Art [the writing teacher] to look up 'virtually'.

4. In our meeting, Art suggested actually. But couldn't virtually be used in this 5. way? I've used it in this way for a long time.

6. I used 'virtually' and 'actually' interchangeably. I feel they have the same

7. meaning. I use them as an alternative to each other to avoid overusing one word.

8. I still feel they are the same.

9. R: Well, let's look them up in the Oxford Advanced Learners' Dictionary.

10. You see, virtually means almost, or very nearly. Actually, there are four

11. meanings. Do you want to read them through?

[The interviewee read for 45 seconds and looked at me.]

12. R: You see, actually is used to emphasise what is true, similar to in fact, right? 
13. J: Yes. They are different. Thank you.

14. R: Any other feedback you feel confused in this paragraph?

15. J: No.

16. R: Ok. I found you changed this part here (pointing to revealed by fishbone).

17. J: In our meeting with Art, I learned if I used hidden, it sounded like something that

18. was a component of the fishbone.

19. R: Enhen. So?

20. J: As Art suggested, I changed it to revealed by fishbone.

21. R: How do you think about his suggestion?

22. J: I felt if I used hidden in fishbone, if you translate it into Chinese, it is more

23. meaningful. It does not make that sense in English.

24. I think Art's suggestion was right.

Because Jin expressed her confusion about the difference between virtually and actually in Line 2, teacher feedback on virtually was categorised as TF/used/not understood. By contrast, as it can be seen in Lines 17-24, Jin has comprehended the problem with hidden in fishbone; therefore, she changed it to revealed by fishbone as a response to teacher feedback. Hence, teacher feedback on hidden in fishbone was coded as TF/used/understood.

Two approaches were adopted to ensure reliability of the analysis of SRI data. Two dictionaries (i.e. Oxford Advanced Learner's Dictionary and Merriam-Webster dictionary) were utilised to assist in identifying the legitimacy of interviewees' explanations for why a feedback point was used. In addition, two colleagues with experiences of analysing learner's language were asked to code two sets of SRI data in terms of understood and not 
understood with the first version of the coding scheme. Their coding results were then compared with the researcher's. Only a few areas of disagreement were found. These areas were discussed and amendments were made to the coding scheme. This yielded the coding scheme in Appendix B. Another set of data was coded by the two colleagues and the researcher. An agreement rate of 0.95 was reached.

\subsubsection{Interview data}

Semi-structured interviews were carried out at the end of the study, to capture the factors that affected students' decision-making process of using peer and teacher feedback in their redrafts. Eleven volunteer students were interviewed. The interview data were archived, coded and analysed via NVivo2. A grounded approach was adopted, letting the interview data suggest categories by themselves.

\section{Findings}

The findings are reported here in order of the research questions: (a) the use frequency of peer and teacher feedback, (b) the amount of peer and teacher feedback that was used and understood, and (c) factors that were reported to impact students' responses to peer and teacher feedback when revising their drafts.

\subsection{Use frequency of peer and teacher feedback}

It can be seen in Table 2 that the students incorporated $74 \%$ of teacher feedback instances when revising their drafts, with a mean of 15.69. A contrast to teacher feedback, only $46 \%$ of peer feedback points were integrated in learners' revised drafts, with a mean of 4.12. However, the SD values suggest a greater variety of the use frequency of teacher than peer feedback (12.35 against 3.41) in individual writing assignments, probably 
because of the bigger variety of amount of teacher feedback provided on individual papers (i.e. 13.02 for teacher feedback against 6.54 for peer feedback).

A paired-sample t-test found that the difference in the mean of the use frequency of peer and teacher feedback was significant, $t(25)=5.55, p=.000$, with a mean difference as 11.57. This suggests that the students used a significantly 11.57 more teacher than peer feedback on average in the 26 assignments.

The results show that teacher feedback triggered more revisions than peer feedback in this study. This is not surprising as nearly all the existing investigations of peer feedback in ESL/EFL writing reported a higher use frequency of teacher than peer feedback (see section 1). However, as discussed in Section 2.1.2, the amount of peer feedback being used in learners' redrafts could be influenced by the teacher's comments on peer feedback. It is possible that the learners tended to incorporate peer feedback that was agreed by the teacher and vice versa. It is also possible that the learners used less peer feedback if the teacher did not comment on peer feedback due to their uncertainty about the quality of peer feedback (see Section 1). This is beyond the scope of this study but worthy of further investigation in future research.

\subsection{Amount of peer and teacher feedback that was understood}

Table 3 shows the amount of peer and teacher feedback that was used and understood, yielded by stimulated recall interviews. Among the 107 peer feedback instances that were used in students' revisions, $83 \%$ were fully understood by the students. The small SD value (i.e. 2.16) further suggests that the mean amount of peer feedback that was used and understood (i.e. 3.42) varied little from each assignment. By contrast, only 58\% (i.e. 237 out of 408) of teacher feedback instances were found to be used with a real understanding 
of their necessity. Although the $S D$ value of the mean of teacher feedback that was used and understood is bigger than that of peer feedback, 4.63 still suggests the existence of small variation among each writing piece. In this sense, most students understood less than $60 \%$ of the teacher feedback that they incorporated into their revisions.

Based on the SRI results of learners' understanding of peer and teacher feedback that was used in their redrafts, we notice that the students in this study sometimes used feedback without understanding; further, a larger portion of teacher feedback was found to be un-understood. This triggered the investigation of factors that made this occur.

\subsection{Factors influencing students' decision to use peer and teacher feedback}

With reference to student interview data about how they reacted to peer and teacher feedback, two factors were reiterated most frequently: the different nature of peer and teacher feedback and the role of first language (L1) in peer interaction.

\subsubsection{Different nature of peer and teacher feedback}

The students explained their different attitudes towards peer and teacher feedback. For example, Ren asserted that:

I view teacher feedback as the revision requirement but peer feedback as suggestions. He is a native speaker and he is the teacher... Whether an essay is good or not is in a teacher's capable hands. (Ren/25052006/L39)

Ren regarded teacher feedback as requirements that she must follow when dealing with her draft because in the end the teacher was the sole legitimate agent to mark her writing. By contrast, she regarded peer feedback as suggestions that could be followed or discarded. In this sense, learners' responses to peer and teacher feedback were influenced by the assessment culture that the teacher was the ultimate judger of students' writing quality. 
This hints the importance of raising the profile of peer feedback in the final mark of students' writing so that the students would take peer feedback more seriously. Another student, Dan, illuminated how she considered peer and teacher feedback as follows:

I accept teacher feedback more passively whereas peer feedback more actively. Passive, I mean the teacher explains to me about the problem, I think it sounds convincing so I accept it. As for peer feedback, I would discuss it if I feel confused about it.... Peer feedback is discussed more interactively. It is not only feedback. It is feed forward and feed back between us. Therefore, we have a clear idea of which instance should be used and which will not be used. But teacher feedback, it is more authoritative. (Dan/24052006/L23-29)

In Dan's view, the authoritative nature of teacher feedback made her less willing to challenge teacher feedback; instead, even if she did not fully understand teacher feedback (sounds convincing), she might still integrate it into her revised drafts. By contrast, she felt ease to discuss the peer feedback that she felt confused before using it in her redrafts.

We can thus conclude that the teacher's dominant role in students' previous learning experiences of English writing described in Section 2.1.1 made students hesitate to question the necessity of teacher feedback before using it in their revisions. The relative equal social status among students, however, made them willing and brave enough to challenge peer feedback before deciding whether the peer feedback should be used. This provides an explanation for why the students used more teacher feedback without understanding the reasons behind it.

\subsubsection{Use of first language in peer interaction}


In addition to the different nature of peer and teacher feedback perceived by the students, the use of L1 (i.e. Mandarin Chinese) in peer interaction was presented as another important cause of learners' better understanding of peer feedback. Six of the eleven interviewees emphasised that the use of their L1 in peer interaction assisted them in understanding peers and being understood by peers. An example was given by Ping: When you discussed with peers, you may use Chinese if you don't know how to express yourself in English. But it is impossible to use Chinese when we are discussing with Art [the writing tutor], so we could not reach mutual understanding of some feedback points. (Ping/23052006/L23-25)

Moreover, since the students were reluctant to probe teachers as indicated in Section 3.3.1, even if they could not reach understanding, they probably avoided further discussions with the teacher. This explains why a large portion of teacher feedback that was used but un-understood.

The facilitative role of $\mathrm{L} 1$ in peer interaction aligns with socio-cultural theory that language is the most essential tool to mediate language development with social interaction (Lantolf, 2003; Lantolf \& Thorne, 2006; Vygotsky, 1978). It also corroborates Swain's (2000) assertion that language that has been learned serves to mediate further language development. It echoes in this study as the use of L1 promoting the efficiency of peer interaction for developing Chinese learners' EFL writing proficiency. The use of L1 to facilitate peer interaction was also observed in Guerrero and Villamil's (1994) ESL writing classes where the 54 university English learners utilised their L1 (i.e. Spanish) to help them to be better understood by their peers.

\section{Discussions and conclusions}


This study observed that the students integrated significantly more teacher feedback than peer feedback in their redrafts ( $74 \%$ against $46 \%)$; however, they understood a larger portion of peer feedback than teacher feedback that was used in redrafts $(83 \%$ in contrast to $58 \%$ ). This is because (a) the students viewed teacher feedback to be more important and more trustworthy than peer feedback and (b) L1 facilitated mutual understanding in peer interaction.

The difference in the amount of feedback that was used and that was understood corroborates the existing findings that learners sometimes use feedback in their redrafts without understanding its necessity (Goldstein, 2006; Hyland, 1998; Lee, 2007). This reveals the importance of raising learners' awareness that understanding feedback should be the prerequisite of using it. The writing teacher shall integrate a learning task to promote learners' understanding of feedback, for instance, by asking learners to discuss their understanding of feedback with their peers. Furthermore, this study found that the learners integrated a larger percentage of teacher feedback than peer feedback without full understanding. This indicates that if a similar amount of teacher feedback and peer feedback was used in learners' redrafts, learners would acquire more knowledge from peer than teacher feedback. This poses a challenge to the appropriateness of the research enquiry that suggested a greater value of teacher than peer feedback for ESL/EFL writing in terms of the larger amount of teacher than peer feedback that was used in learners' redrafts. As this study demonstrated, learners' understanding of feedback shall be regarded as an at least equally essential aspect as learners' use of feedback for suggesting whether and how peer and teacher feedback mediates ESL/EFL writing development. This reflects Lantolf's emphasis on the crucial role of understanding in language development with other 
regulation: A mere transmission of the external form on the internal plane could be no language development (e.g. Lantolf, 2000; Lantolf, 2003; Lantolf \& Appel, 1994; Lantolf \& Thorne, 2006; Mitchell \& Myles, 2004).

The two factors that led to learners' better understanding of peer feedback indicate the importance of raising the profile of peer feedback in writing assessment. They also suggest that learners' previous learning experiences of English writing affected their perceptions of and responses to, peer and teacher feedback. In this study, the students' long-term teacherdriven learning experiences induced their biased views of peer and teacher feedback which consequently led to their differed revision act on peer and teacher feedback. This aligns with Cheng's (2000) proposal that teacher-centred learning experience is a plausible interpretation for Asian English learners' resistance to peer collaboration. It also corroborates the results in Carson and Nelson's series studies with Chinese English learners that the entrenched teacher-dominated learning experiences negatively influenced learners' reactions to peer feedback (Carson \& Nelson, 1994, 1996; Nelson \& Carson, 1998). The facilitative role of L1 in peer interaction raises the issue on the use of L1 in an ESL/EFL writing class, specifically on how to balance the use of L1 in the ESL/EFL class to maximise learners' use of target language whilst maximise learners' understanding of feedback. On the other hand, the facilitative role of L1 also indicates the impact of learners' limited ESL/EFL proficiency on the use of peer feedback, as suggested in other empirical studies (W. Cheng \& Warren, 2005; Liu \& Sadler, 2003; Mangelsdorf \& Schlumberger, 1992; Nelson \& Murphy, 1992; Oscarson, 1997; Storch, 2005). This sheds light on the necessity of taking into consideration learners' ESL/EFL proficiency when designing how peer feedback shall be integrated into class. 
To sum up, the findings in this study suggest that it will be problematic to compare the value of peer and teacher feedback on writing by simply counting its use frequency in learners' subsequent drafts. This study has evidenced that learners' use of feedback in their redrafts does not necessarily mean their acquisition of knowledge behind it. This study thus implies that learners' use and understanding of feedback should be viewed as two equally important factors for deciding whether peer feedback should be integrated with teacher feedback in ESL/EFL writing classes. Learners' better understanding of peer feedback that was used also substantiates Lantolf and Thorner (2006)'s assertion that peer interaction should be included among participant structures conducive to learning through the ZPD, especially in secondary and higher education settings (p.286). 


\section{References}

Berg, E. C. (1999). The effects of trained peer response on ESL students' revision types and writing quality. Journal of Second Language Writing, 8(3), 215-241.

Carson, J. G., \& Nelson, G. L. (1994). Writing groups: cross-cultural issues. Journal of Second Language Writing, 3(1), 17-30.

Carson, J. G., \& Nelson, G. L. (1996). Chinese students' perceptions of ESL peer response group interaction. Journal of Second Language Writing, 5(1), 1-19.

Chapman, D. W., \& Carter, J. F. (1979). Translation procedures for the cross cultural use of measurement instruments. Educational evaluation and policy analysis, 1(3), 7176.

Cheng, W., \& Warren, M. (2005). Peer assessment of language proficiency. Language Testing, 22(1), 93--121.

Cheng, X. (2000). Asian students' reticence revisited. System, 28, 435-446.

Connor, U., \& Asenavage, K. (1994). Peer response groups in ESL writing classes: how much impact on revision. Journal of Second Language Writing, 3(3), 256-276.

Foster, P., \& Ohta, A. S. (2005). Negotiation for meaning and peer assistance in second language classroom. Applied Linguistics, 26(3), 402-430.

Gass, S. M., \& Mackey, A. (2000). Stimulated recall methodology in second language research. London: Lawrence Erlbaum Associations, Publishers.

Goldstein, L. (2006). Feedback and revision in second language writing: contextual, teacher, and student variables. In K. Hyland \& F. Hyland (Eds.), Feedback in second language writing: contexts and issues. Cambridge: Cambridge University Press.

Guerrero, M., \& Villamil, O. S. (1994). Social-cognitive dimensions of interaction in L2 peer revision. The Modern Language Journal, 78(4), 484-496.

Hansen, J. G., \& Liu, J. (2005). Guiding principles for effective peer response. ELT J, $59(1), 31-38$.

Hu, G. (2005). Using peer review with Chinese ESL student writers. Language Teaching Research, 9(3), 321-342. 
Hyland, F. (1998). The impact of teacher written feedback on individual writers. Journal of Second Language Writing, 7(3), 255-286.

Lantolf, J. P. (2000). Sociocultural theory and second language learning. Oxford: Oxford University Press.

Lantolf, J. P. (2003). Intrapersonal communication and internalization in the second language classroom. In A. Kozulin (Ed.), Vygotsky's educational theory in cultural context Cambridge: Cambridge University Press.

Lantolf, J. P., \& Appel, B. (1994). Vygotskian approaches to second language research. Westport: Ablex Publishing Corporation

Lantolf, J. P., \& Thorne, S. L. (2006). Sociocultural theory and the genesis of second language development. Oxford: Oxford University Press.

Lee, I. (2007). Feedback in Hong Kong secondary writing classrooms: Assessment for learning or assessment of learning? Assessing Writing, 12(3), 180-198.

Liu, J., \& Sadler, R. W. (2003). The effect and affect of peer review in electronic versus traditional modes of L2 writing. Journal of English for Academic Purpose, 2(3), 193-227.

Mangelsdorf, K., \& Schlumberger, A. (1992). ESL student response stances in a peerreview task. Journal of Second Language Writing, 1(3), 235-254.

Min, H.-T. (2005). Training students to become successful peer reviewers. System, 33(2), 293-308.

Mitchell, R., \& Myles, F. (2004). Second language learning theories. London: Arnold.

Nelson, G., \& Carson, J. (1998). ESL students' perceptions of effectiveness in peer response groups. Journal of Second Language Writing, 7(2), 113-131.

Nelson, G., \& Murphy, J. (1992). An L2 writing group: task and social dimensions. Journal of Second Language Writing, 1(3), 171-193.

Oscarson, M. (1997). Self-assessment of foreign and second language proficiency. Language Testing and Assessment, 7.

Patri, M. (2002). The influence of peer feedback on self- and peer-assessment of oral skills. Language Testing, 19(2), 109-133. 
Paulus, T. M. (1999). The effect of peer and teacher feedback on student writing. Journal of Second Language Writing, 8(3), 265-289.

Richards, L. (1999). Using NVivo in qualitative research. London: SAGE Publications.

Rollinson, P. (2005). Using peer feedback in the ESL writing class. ELT Journal, 59(1), 23-30.

Stake, R. E. (1995). The art of case study research. London: SAGE Publications.

Stanley, J. (1992). Coaching student writers to be effective peer evaluators. Journal of second language writing, 1(3), 217-233.

Storch, N. (2005). Collaborative writing: product, process and students' reflections. Journal of Second Language Writing, 14, 153-173.

Swain, M. (2000). The output hypothesis and beyond: mediating acquisition through collaborative dialogue. In J. P. Lantolf (Ed.), Sociocultural theory and second language learning. Oxford: Oxford University Press.

Tsui, A., \& Ng, M. (2000). Do secondary L2 writers benefit from peer comments? Journal of Second Language Writing, 9(2), 147-170.

Villamil, O. S., \& Guerrero, M. C. M. D. (2006). Socio-cultural theory: a framework for understanding the socio-cognitive dimensions of peer feedback. In K. Hyland \& F. Hyland (Eds.), Feedback in second language writing: contexts and issues. Cambridge: Cambridge University Press.

Vygotsky, L. S. (1978). Mind in society: the development of higher psychological process. Cambridge: Cambridge University Press.

Yang, M., Badger, R., \& Yu, Z. (2006). A comparative study of peer and teacher feedback in a Chinese EFL writing class. Journal of Second Language Writing, 15(3), 179200.

Zhang, S. (1995). Reexamining the affective advantage of peer feedback in the ESL writing class. Journal of Second Language Writing, 4(3), 209-222.

Zhu, W. (1995). Effects of training for peer response on students' comments and interaction. Written Communication, 12(4), 492-528. 
Appendix A. Student writing sample 
Behaviors that separate us

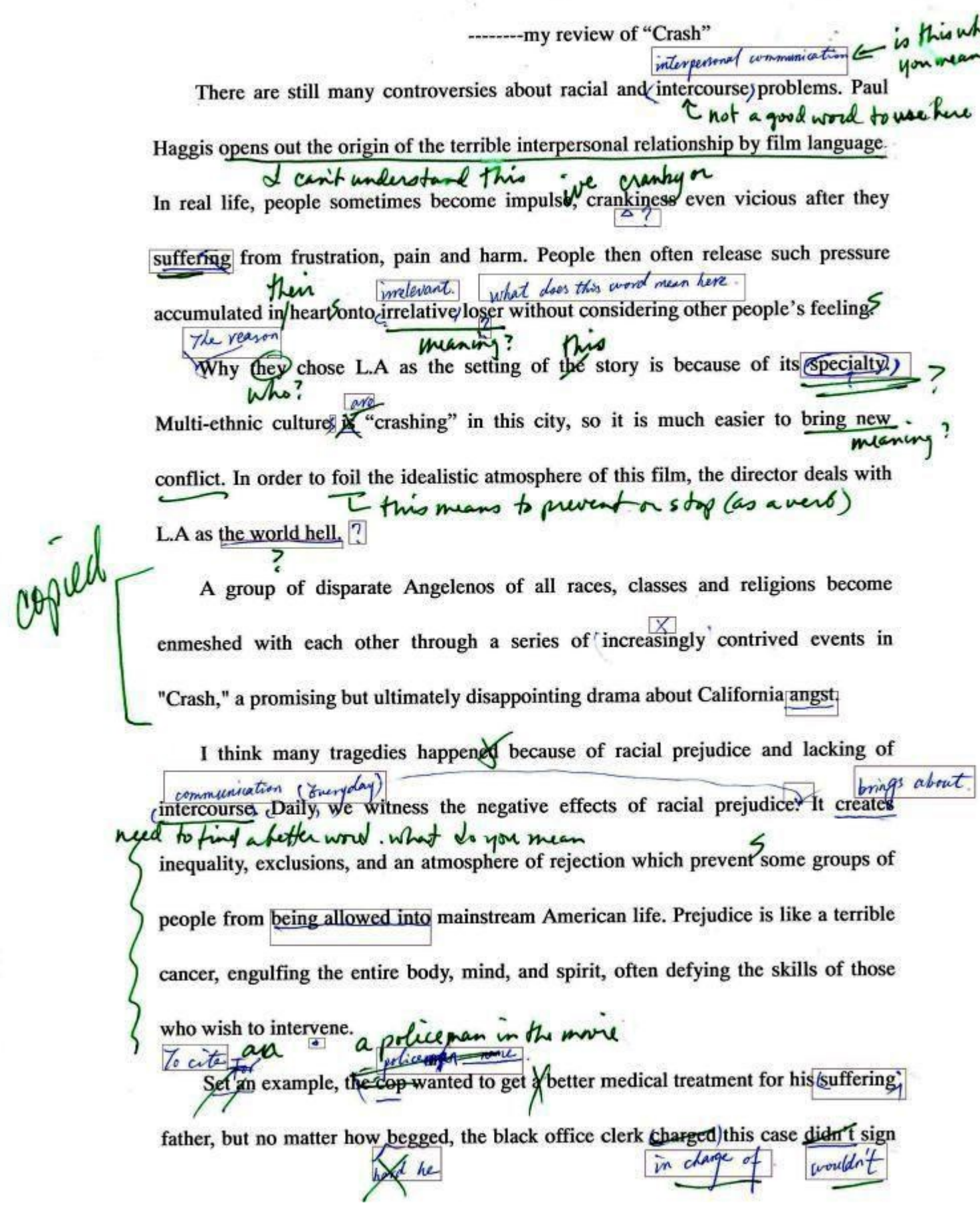

Note: Peer feedback has been put in a box by the researcher.

\section{Appendix B. Coding scheme of learners' understanding of feedback}




\begin{tabular}{|c|c|c|}
\hline Category & Definition & Example \\
\hline $\begin{array}{l}\text { Feedback was } \\
\text { categorised as } \\
\text { understood if }\end{array}$ & $\begin{array}{l}\text { Writers correctly interpreted } \\
\text { why the feedback was } \\
\text { provided. } \\
\text { Writers explained how they } \\
\text { figured out revision } \\
\text { solutions on the basis of the } \\
\text { feedback. } \\
\text { Writers explained how the } \\
\text { feedback helped to improve } \\
\text { their writing quality. }\end{array}$ & $\begin{array}{l}\text { Zhu: Position is more formal } \\
\text { than job, as Art suggested. So I } \\
\text { changed job to position here. } \\
\text { - Yao: He put a question mark } \\
\text { here. I guess he meant why I } \\
\text { thought so, so I added the reason } \\
\text { afterwards. } \\
\text { - Wang: My peer thought I } \\
\text { overused I am and I was, so I } \\
\text { should change I was an editor to } \\
\text { I edited. I think it was a good } \\
\text { suggestion. }\end{array}$ \\
\hline $\begin{array}{l}\text { Feedback was } \\
\text { categorised as } \\
\text { not understood } \\
\text { if }\end{array}$ & $\begin{array}{l}\text { Writers asked the researcher } \\
\text { to explain the feedback that } \\
\text { was used in their revisions. } \\
\text { - Writers confessed that they } \\
\text { only copied the feedback } \\
\text { point. } \\
\text { - Writers deleted the part } \\
\text { addressed by the feedback } \\
\text { because they did not know } \\
\text { how to integrate the received } \\
\text { feedback. } \\
\text { - Writers expressed their } \\
\text { confusion over the feedback } \\
\text { that they used in their } \\
\text { revisions. } \\
\text { - Writers turned to } \\
\text { dictionaries when asked to } \\
\text { explain their use of a } \\
\text { feedback point. }\end{array}$ & $\begin{array}{l}\text { - Shen: Here, could I ask you why } \\
\text { I couldn't use since here? } \\
\text { - Gao: I don't know. I just copied } \\
\text { his feedback. I wrote the second } \\
\text { draft just before the class. } \\
\text { - Zhang: I don't know how to } \\
\text { integrate the feedback point so I } \\
\text { deleted this part. }\end{array}$ \\
\hline
\end{tabular}

